\title{
Serum endothelin-1 and NT-proBNP, but not ADMA, endoglin and TIMP-1 levels, reflect impaired right ventricular function in patients with systemic sclerosis
}

\author{
Michal Ciurzyński • Piotr Bienias • Katarzyna Irzyk • Maciej Kostrubiec • \\ Zbigniew Bartoszewicz • Maria Siwicka • Anna Stelmaszczyk-Emmel • \\ Elżbieta Górska • Urszula Demkow • Piotr Pruszczyk
}

Received: 21 March 2013 /Revised: 6 July 2013 / Accepted: 26 July 2013 /Published online: 14 August 2013

(C) The Author(s) 2013. This article is published with open access at Springerlink.com

\begin{abstract}
Background Heart and pulmonary involvement is a leading cause of systemic sclerosis (SSc)-related deaths.

Objectives The aim of our study was to assess if biochemical markers of right ventricular (RV) overload, endothelial function and collagen metabolism can predict RV dysfunction assessed by Doppler echocardiography in SSc patients.

Methods We prospectively studied 111 consecutive patients (101 F, $10 \mathrm{M}$, age $54.2 \pm 13.8$ years) with diagnosed SSc (mean disease duration $9.4 \pm 11.4$ years) and a group of 21 age-matched subjects ( $18 \mathrm{~F}, 3 \mathrm{M}$, age $49.3+10.5$ years). We performed transthoracic echocardiography (Phillips iE 33) and measured serum endothelin-1 (ET-1), N-terminal pro-brain natriuretic peptide (NT-proBNP), asymmetric dimethylarginine (ADMA), endoglin and human tissue inhibitor of matrix metalloproteinase (TIMP-1) concentration.

Results Median serum NT-proBNP level in SSc patients was 133.5 (range $21.86-17,670 \mathrm{pg} / \mathrm{ml}$ ) and was significantly
\end{abstract}

M. Ciurzyński $(\varangle) \cdot$ P. Bienias $\cdot$ K. Irzyk $\cdot$ M. Kostrubiec $\cdot$

P. Pruszczyk

Department of Internal Medicine and Cardiology,

Medical University of Warsaw, Warsaw, Poland

e-mail: michal.ciurzynski@wum.edu.pl

\section{Z. Bartoszewicz}

Department of Internal Medicine and Endocrinology,

Medical University of Warsaw, Warsaw, Poland

Z. Bartoszewicz

Department of Endocrinology, Warsaw Medical Research Centre of Polish Academy of Science, Warsaw, Poland

\section{Siwicka}

Department of Dermatology, Medical University of Warsaw,

Warsaw, Poland

A. Stelmaszczyk-Emmel • E. Górska • U. Demkow

Department of Laboratory Diagnostics and Clinical Immunology of Developmental Age, Medical University of Warsaw, Warsaw, Poland higher than in controls $(p=0.0002)$. Moreover, the median serum ET-1 level of 1.49 (range $0.26-8.75 \mathrm{pg} / \mathrm{ml}$ ) was higher in SSc patients $(p=0.002)$. However, no significant differences in ADMA, TIMP-1 and endoglin serum concentration between SSc patients and controls were observed. Serum NTproBNP concentration correlated positively with echocardiographic signs of RV overload: tricuspid regurgitation pressure gradient $(r=0.38, p=0.0004)$ and RV Tei index $(r=0.25, p=$ $0.01)$. ET-1 serum level correlated negatively with tricuspid annular plane systolic excursion $(r=-0.4, p=0.01)$ and positively with inferior vena cava diameter measured at expiration $(r=0.38, p=0.0002)$. The echocardiographic signs of RV overload were significantly more pronounced in the highest NT-proBNP tertile ( $>195 \mathrm{pg} / \mathrm{ml}$ ) group than in the lowest one $(<88 \mathrm{pg} / \mathrm{ml})$.

Conclusions Serum ET-1 and NT-proBNP, but not endoglin, ADMA and TIMP-1 levels correlating with the echocardiographic parameters of RV overload, can be considered as noninvasive indicators of RV dysfunction in SSc patients.

Keywords Biomarkers · Echocardiography $\cdot$ Pulmonary hypertension $\cdot$ Systemic sclerosis

\section{Introduction}

Systemic sclerosis ( $\mathrm{SSc}$ ) is a connective tissue disease characterized by vascular inflammation and immunologically mediated fibrosis of the skin and various organs including the cardiovascular system. Cardiopulmonary complications adversely influence the prognosis in SSc patients $[1,2]$. According to the recent systematic review and meta-analysis of cohort studies, the pooled standardized mortality ratio among SSc patients was 3.5 (95 \% CI 3.03-4.11), and mortality did not significantly change over the past 40 years [3]. Komocsi et al. analysed 18 studies comprising a total of 
12,829 SSc patients. The reported causes of death were $19.7 \%$ cardiac, $16.8 \%$ interstitial pulmonary disease and $13.1 \%$ pulmonary hypertension [4].

Potentially, identification of noninvasive predictors of right ventricular (RV) dysfunction may allow early detection of cardiac involvement and may help to select patients for further invasive evaluation [5]. Echocardiography is a widely available noninvasive diagnostic tool for RV dysfunction detection. Recent guidelines of the European Society of Cardiology (ESC) for the diagnosis and treatment of pulmonary hypertension suggest considering annual echocardiographic assessment of SSc patients even if they remain asymptomatic [6]. However, over the last years, a variety of biochemical biomarkers have been identified to be important in the assessment of SSc patients. There is increasing evidence that $\mathrm{N}$-terminal pro-brain natriuretic peptide (NT-proBNP) and endothelin-1 (ET-1) serum levels are elevated in patients with SSc and RV dysfunction [7-9]. Moreover, asymmetric dimethylarginine (ADMA), a parameter of endothelial dysfunction, and endoglin, an important modulator of endothelial vasomotor tone, also have been found to be elevated in this group of patients $[10,11]$. Interestingly, it was observed that the serum concentration of the tissue inhibitor of metalloproteinase 1 (TIMP-1), a marker of decreased collagen metabolism, is increased in patients with $\mathrm{SSc}$ and correlates with ADMA serum level which may suggest an association between endothelial dysfunction and matrix remodelling [12].

The aim of our study was to assess if biochemical markers of right ventricular overload, endothelial dysfunction and collagen metabolism can predict RV impairment assessed by Doppler echocardiography in SSc patients.

\section{Materials and methods}

One hundred eleven consecutive patients with confirmed SSc (101 females, 10 males, mean age 54.2 \pm 13.7 ) with mean time of $9.4 \pm 11.4$ years from SSc diagnosis were prospectively included into the study. SSc was diagnosed according to the American College of Rheumatology criteria [13]. Patients with diffuse SSc or limited scleroderma were recruited. Forty-seven (42\%) patients were classified as having diffuse SSc, while 64 (58 \%) had limited SSc. Clinical characterization of patients with $\mathrm{SSc}$ was performed according to the European Scleroderma Trial and Research recommendations [14]. Evaluation of signs and symptoms of SSc was performed in all patients at the onset of the study. In all SSc patients, pulmonary involvement was assessed by chest radiography, HRCT (Toshiba Aquilion 64), pulmonary function testing and measurement of single-breath diffusing lung capacity for carbon monoxide (DLCO) (Sensor Medics, Yorba Linda, USA).

Patients with cardiovascular disorders such as coronary artery disease (angina pectoris, previous myocardial infarction,
ECG and/or echocardiographic signs of myocardial ischaemia), atrial fibrillation, cardiac pacing, significant valvular abnormalities and left ventricular (LV) hypertrophy (intraventricular septum and posterior wall $>11 \mathrm{~mm}$ in echocardiographic examination) were excluded from the current study. Moreover, SSc patients with significant pulmonary functional abnormalities (defined by forced vital capacity [FVC], total lung capacity [TLC] or forced expiratory volume in $1 \mathrm{~s}\left[\mathrm{FEV}_{1}\right]<60 \%$ of predicted) were also not included. We also did not include patients with significant fibrotic changes in the lung by highresolution computed tomography (Kazerooni fibrosis score 216). An impaired renal function with creatinine clearance calculated by the Modification of Diet in Renal Disease Study Group formula below $60 \mathrm{ml} / \mathrm{min} / 1.73 \mathrm{~m}^{2}$ was also an exclusion criterion.

We assessed 21 age- and sex-matched subjects (18 females, 3 males, mean age $49.3 \pm 10.5$ years) as a control group. Special attention was directed to selection of the control group with the same profile of coexisting systemic hypertension and the same cardiologic therapy used as the SSc patients. These subjects had no data for pulmonary diseases and presented no echocardiographic evidence of structural heart disease.

All patients and control subjects gave informed consent, and the protocol of the study was approved by the local Institutional ethics Committee (Medical University of Warsaw ethics Committee, no. KB66/2006).

\section{Serological parameters}

Standard techniques were used to screen all patients for the following serological markers: anti-nuclear antibody (ANA), anti-centromere antibody (ACA) and anti-nucleolar antibody (ANoA) by indirect immunofluorescence on monkey oesophagus at a dilution of serum of 1:20 and on Hep 2 cell line at a dilution of 1:40. Anti-extractable nuclear antigen antibodies, including Scl-70 antibodies, were identified by double immunodiffusion.

\section{Blood sampling and assays}

At the same day when echocardiography was performed, fasting blood samples were collected by venipuncture and centrifuged. Sera were stored at $-70{ }^{\circ} \mathrm{C}$ until assayed.

The concentration of NT-proBNP was analysed on an Elecsys 2010 automatic analyzer (Roche Diagnostics, Basel, Switzerland). Serum NT-proBNP concentration higher than $125 \mathrm{pg} / \mathrm{ml}$ was regarded as abnormal as indicated by the producer.

The concentration of endothelin-1 was measured with the use of the QuantiGlo Human Endothelin-1 immunoassay kit (cat. no. QET00B, R\&D Systems, Inc., Minneapolis, MN, USA) according to the manufacturer's protocol. A Fluoroskan Ascent FL microplate luminometer (Thermo Labsystems Oy, 
Helsinki, Finland) was used to measure the intensity of the light emitted, and Ascent Software, v. 2.6, was used for creation of standard curves, curve fitting and calculations of concentrations. To detect endoglin, a commercial immunoenzymatic kit, QuantiGlo Human Endoglin/CD 105 immunoassay kit (cat. no. DNDG00, R\&D Systems, Inc., Minneapolis, MN, USA), was used. The concentration of ADMA was measured using a commercial immunoenzymatic kit (ADMA Elisa Kit, Immunodiagnostik AG, Germany). A commercial immunoenzymatic kit, Human TIMP-1 Immunoassay (R\&D Systems, Inc., Minneapolis, MN, USA), was used to detect TIMP-1.

Tests detecting endoglin, ADMA and TIMP-1 were based on a solid double-antibody sandwich ELISA. Sera were added to microwells precoated with antibodies against detected antigen. All samples were assayed in duplicates. In the positive cases, antigen-antibody complex reacted with peroxidaselabelled antihuman IgG conjugate. Using $\mathrm{H}_{2} \mathrm{O}_{2} / \mathrm{TMB}$ as substrate, the enzymatic activity of peroxidase was measured at $450 \mathrm{~nm}$ with the use of the automated reading system Asys UVM 340. All the results were referred to the standard curve. The standards were provided for the generation of a semilogarithmic reference curve. Immunoenzymatic assays were performed blindly by a laboratory technician according to the manufacturer instruction.

\section{Echocardiography}

Echocardiographic examination was performed with Philips iE 33 (Andover, Md., USA) with 2.5-3.5-MHz transducers. Patients were examined in the left lateral position. The dimensions of the right and left ventricles were measured in the parasternal long-axis view and apical four chamber view in late diastole defined by the $\mathrm{R}$ wave of continuously monitored ECG lead. From the subcostal approach, vena cava dimensions at spontaneous inspiration and expiration were measured. After the recording of the tricuspid valve peak systolic velocity with continuous-wave Doppler echocardiography, the tricuspid regurgitation peak gradient (TRPG) was calculated according the simplified Bernoulli equation. Pulmonary hypertension $(\mathrm{PH})$ was suspected according to ESC criteria when TRPG $>31 \mathrm{mmHg}$ (tricuspid regurgitant velocity $>2.8 \mathrm{~m} / \mathrm{s}$ ) [6]. Patients in whom $(\mathrm{PH})$ was suspected were directed to right heart catheterisation. Acceleration time of pulmonary ejection (AcT) was measured using pulse wave Doppler with sample volume placed in the RV outflow tract just below the pulmonary valve. Measurements were averaged over five consecutive heart cycles. The Tei index for the right ventricle was calculated by dividing the sum of RV isovolumetric contraction and relaxation time by RV ejection time, as has been described previously [15]. In order to assess the right ventricular function using one-dimensional M-mode echocardiography, the tricuspid annular peak systolic excursion (TAPSE) was measured. The LV ejection fraction (EF) was calculated according to the modified Simpson rule using apical four- and two-chamber views [16].

Six-minute walk test

The 6-min walk test (6MWT) was performed on a level hallway surface in accordance with the American Thoracic Society guidelines [17].

Statistical analysis

Data characterized by a normal distribution are expressed as a mean followed by a standard deviation. Biochemical parameters are expressed both as a mean followed by a standard deviation and as a median with a range. Patients with SSc and controls were compared with the Wilcoxon test depending on the character of parameter distribution. For categorical variables, the differences between the groups were compared with Chi squared test or Fisher's exact test. Correlations between echocardiographic and biochemical variables were evaluated by Spearman's correlation coefficients. Receiver-operating characteristic (ROC) analysis was performed for the selection of the optimal cut-off value of the NT-proBNP and ET-1 levels for the prediction of TRPG $>31 \mathrm{mmHg}$ and RV Tei index $>0.4$.

An analysis was performed using a statistical software package (SAS 9.2). $p<0.05$ was considered statistically significant.

\section{Results}

A total of 111 SSc patients and 21 control subjects were enrolled in this study. The general characteristics of the study population and control group are summarized in Table 1.

Treatment

Thirty-one (28\%) SSc patients were treated with the angiotensin-converting enzyme inhibitors (ACE-I), while

Table 1 The general parameters in the SSc and the control groups

\begin{tabular}{llll}
\hline Parameter & $\begin{array}{l}\text { SSc patients } \\
(n=111)\end{array}$ & $\begin{array}{l}\text { Control subjects } \\
(n=21)\end{array}$ & $p$ value \\
\hline Age (years) & $54.2 \pm 13.7$ & $49.3 \pm 10.5$ & NS \\
Gender (F/M) (no.) & $101 / 10$ & $18 / 3$ & NS \\
Body surface area (m $\left.{ }^{2}\right)$ & $1.73 \pm 0.26$ & $1.72 \pm 0.18$ & NS \\
Heart rate (bpm) & $73.47 \pm 9.45$ & $76.21 \pm 12.38$ & NS \\
Systemic hypertension (\%) & $37(33 \%)$ & $6(29 \%)$ & NS \\
\hline
\end{tabular}


seven of them $(6 \%)$ were treated with angiotensin II receptor antagonists. Ten SSc patients $(9 \%)$ must have been treated with beta blockers, because they had ongoing tachycardia. Sixteen SSc patients (14\%) also received diuretics, and 27 (24\%), calcium channel blockers. Due to the progression of SSc, $15(13.5 \%)$ patients received immunosuppressant agents (glucocorticoids and cyclophosphamide). Also, the control patients received pharmacological treatment, but we did not find significant differences in the use of the cardiological drugs between the SSc and control groups. The main clinical, pulmonary function and serological findings of SSc patients are shown in Table 2.

\section{Echocardiography data}

In Table 3, the echocardiographic parameters and 6MWT data in the SSc group and controls are presented. The left ventricular dimension was similar in both groups; however, the left ventricular systolic function assessed with $\mathrm{EF}$ was statistically lower in SSc patients than in controls. Interestingly, echocardiography revealed significant differences in RV morphology and function. TRPG values exceeding $31 \mathrm{mmHg}$ at rest, suggesting the possibility of $\mathrm{PH}$, were found in $22(20 \%)$ SSc patients, while in all controls, it was below this value. The SSc group presented also other echocardiographic signs of RV overload (Table 3). As we expected, SSc patients presented

Table 2 Clinical, pulmonary function and serological data of $111 \mathrm{SSc}$ patients

\begin{tabular}{ll}
\hline Characteristics & Mean \\
Disease duration (years) & $9.4 \pm 11.4$ \\
$\quad$ Median, range & $5.0(1-25)$ \\
Rodnan score & $6.4 \pm 6.7$ \\
$\quad$ Median, range & $4.0,1-35$ \\
FVC, \% predicted & $100.4 \pm 18.3$ \\
FEV $_{1}, \%$ predicted & $94.7 \pm 19.7$ \\
FEV $_{1} /$ FVC, \% predicted & $79.8 \pm 8.2$ \\
TLC, \% predicted $_{\text {DLCO, \% predicted }(n=59)}$ & $101.9 \pm 17.5$ \\
Cutaneous involvement & $70.7 \pm 19.1$ \\
$\quad$ Diffuse & No. \\
Limited & 47 \\
Autoantibodies & 64 \\
ANA positive & \\
ACA positive & 105 \\
Anti-Scl 70 positive & 34 \\
\hline
\end{tabular}

$F V C$ forced vital capacity, $F E V_{1}$ forced expiratory volume in $1 \mathrm{~s}, T L C$ total lung capacity, $D L C O$ diffusion capacity of the lung for carbon monoxide
Table 3 Echocardiographic and 6MWT parameters in SSc patients and controls

\begin{tabular}{llll}
\hline Variables & $\begin{array}{l}\text { SSc patients } \\
(n=111)\end{array}$ & $\begin{array}{l}\text { Controls } \\
(n=21)\end{array}$ & $p$ value \\
\hline EF (\%) & $65.05 \pm 5.1$ & $67.57 \pm 2.52$ & 0.01 \\
RV 4 chambers (mm) & $28.92 \pm 5.36$ & $25.33 \pm 4.07$ & 0.0029 \\
RV/LV 4 chambers & $0.73 \pm 0.12$ & $0.66 \pm 0.08$ & 0.01 \\
TAPSE (mm) & $22.2 \pm 3.23$ & $24.14 \pm 2.37$ & 0.01 \\
RV Tei index & $0.37 \pm 0.08$ & $0.29 \pm 0.02$ & $<0.0001$ \\
AcT (ms) & $116.46 \pm 21.11$ & $134.76 \pm 16$ & 0.0006 \\
TRPG (mmHg) & $26.67 \pm 6.97$ & $17.78 \pm 4.07$ & $<0.0001$ \\
Pulmonary trunk (mm) & $19.09 \pm 2.28$ & $17.8 \pm 1.43$ & 0.009 \\
IVC expiration (mm) & $13.74 \pm 2.93$ & $9.33 \pm 1.15$ & $<0.0001$ \\
IVC inspiration $(\mathrm{mm})$ & $13.52 \pm 3.11$ & $13.42 \pm 1.59$ & $\mathrm{NS}$ \\
6MWT (m) & $515 \pm 102$ & $563 \pm 60$ & 0.03 \\
\hline
\end{tabular}

$E F$ ejection fraction, $R V$ right ventricle, $L V$ left ventricle, TAPSE tricuspid annulus plane systolic excursion, $A c T$ acceleration time of pulmonary ejection, TRPG tricuspid regurgitant peak gradient, $I V C$ inferior vena cava, 6MWT 6-min walking test

markedly shorter $6 \mathrm{MWT}$ distance than controls $(515 \pm 102$ vs $563 \pm 60 \mathrm{~m} p=0.03$ ).

\section{Plasma biomarker levels}

Biochemical parameters in SSc patients and controls are presented in Table 4. Serum NT-proBNP levels exceeded the reference value $(125 \mathrm{pg} / \mathrm{ml})$ in $50(45 \%) \mathrm{SSc}$ patients. The median serum NT-proBNP level in SSc patients was 133.5 (range $21.86-17,670 \mathrm{pg} / \mathrm{ml}$ ). In all controls, the NT-proBNP serum concentration was below the reference value and was significantly lower than in SS patients. Moreover, in SSc patients, the mean serum ET-1 level was $1.86 \pm 1.4 \mathrm{pg} / \mathrm{ml}$ (median value 1.49 , range $0.26-8.75 \mathrm{pg} / \mathrm{ml}$ ) and was significantly higher than in controls $(p=0.002)$. However, no significant differences in other biomarker serum concentrations between SSc patients and controls were observed (Table 4).

Serum NT-proBNP concentration correlated positively with echocardiographic indices of RV overload: TRPG ( $r=$ $0.38, p=0.0004)$ and RV Tei index $(r=0.25, p=0.01)$. ET-1 serum level correlated negatively with TAPSE $(r=-0.4, p=$ $0.01)$ and positively with inferior vena cava (IVC) diameter measured at expiration $(r=0.38, p=0.0002)$.

We divided the SSc group according to the NT-proBNP serum tertiles. Table 5 presents clinical and echocardiographic parameters in the lowest and highest tertile group of patients according to the NT-proBNP levels.

The echocardiographic signs of RV overload were significantly more pronounced in the highest NT-proBNP tertile group than in the lowest one. Also, the 6MWT distance was significantly shorter in this group. 
Table 4 Biomarker levels in SSc patients and controls

\begin{tabular}{|c|c|c|c|}
\hline Parameter & $\begin{array}{l}\text { SSc patients } \\
(n=111)\end{array}$ & $\begin{array}{l}\text { Controls } \\
(n=21)\end{array}$ & $p$ value \\
\hline $\begin{array}{l}\text { NT-proBNP }(\mathrm{pg} / \mathrm{ml}) \\
\text { Median, range }\end{array}$ & $\begin{array}{l}621.02 \pm 2,565.34 \\
133.5,21.86-17,670\end{array}$ & $\begin{array}{l}62.65 \pm 26.94 \\
62.2,30.8-116\end{array}$ & 0.0002 \\
\hline $\begin{array}{l}\text { Endothelin-1 }(\mathrm{pg} / \mathrm{ml}) \\
\text { Median, range }\end{array}$ & $\begin{array}{l}1.86 \pm 1.4 \\
1.49,0.26-8.75\end{array}$ & $\begin{array}{l}1.23 \pm 0.6 \\
1.16,0.76-3.19\end{array}$ & 0.002 \\
\hline $\begin{array}{l}\text { ADMA ( } \mu \text { mol/l) } \\
\text { Median, range }\end{array}$ & $\begin{array}{l}0.45 \pm 0.14 \\
0.45,0.23-0.99\end{array}$ & $\begin{array}{l}0.46 \pm 0.09 \\
0.44,0.34-0.67\end{array}$ & NS \\
\hline $\begin{array}{r}\text { Endoglin }(\mathrm{ng} / \mathrm{ml}) \\
\text { Median, range }\end{array}$ & $\begin{array}{l}3.43 \pm 0.97 \\
3.22,2.16-6.55\end{array}$ & $\begin{array}{l}3.95 \pm 1.5 \\
4.44,1.29-6.14\end{array}$ & NS \\
\hline $\begin{array}{l}\text { TIMP-1 (ng/ml) } \\
\text { Median, range }\end{array}$ & $\begin{array}{l}167 \pm 63.1 \\
163.4,70.26- \\
316.73\end{array}$ & $\begin{array}{l}182.8 \pm 28.8 \\
179.18,140.62- \\
238.84\end{array}$ & NS \\
\hline
\end{tabular}

ROC analysis in order to define the optimal serum NTproBNP level for TRPG $>31 \mathrm{mmHg}$ detection was also performed. The area under the curve (AUC) was 0.779. A cut-off value of $195 \mathrm{pg} / \mathrm{ml}$ showed sensitivity of $75 \%$, specificity of $67 \%$, positive predictive value (PPV) of $88 \%$ and negative predictive value (NPV) of $43 \%$ for SSc-related $\mathrm{PH}$.

We also performed ROC analysis to define the optimal serum NT-proBNP level for Tei index $>0.4$ detection. The AUC was 0.681 . A cut-off value of $215 \mathrm{pg} / \mathrm{ml}$ revealed sensitivity of $79 \%$, specificity of $57 \%$, PPV of $86 \%$ and NPV of $44 \%$ for Tei index $>0.4$ detection.

A similar analysis was performed to define the optimal serum ET-1 level for Tei index $>0.4$ detection. The AUC was 0.618 . A cut-off value of $1.85 \mathrm{pg} / \mathrm{ml}$ showed sensitivity of $69 \%$, specificity of $52 \%$, PPV of $83 \%$ and NPV of $34 \%$ for Tei index $>0.4$.

\section{Discussion}

Pulmonary hypertension is the most common cause of scleroderma-related morbidity and mortality [18, 19]. Early detection of RV dysfunction even in asymptomatic patients seems to be important for their prognosis. In the present study, we assessed several biochemical biomarkers and their relation with echocardiographic parameters of RV dysfunction. According to the recent ESC guidelines, TRPG $>31 \mathrm{mmHg}$ may suggest PH [6]. In our study, TRPG was significantly higher in SSc patients than in the control group. Moreover, in SSc patients, we found both the RV and pulmonary trunk diameters to be significantly increased, which may suggest RV pressure overload. RV Tei index, an accepted global ventricular function parameter, was markedly increased in SSc patients indicating decreased RV performance [6, 20]. Tei et al. reported a significant increase in the mean value of the Tei index in 26 patients with pulmonary arterial hypertension (PAH) compared to 37 controls. They also revealed the prognostic value of this parameter [15]. Similar data were published by Yeo et al. [21]. Sebbeg et al. reported that changes in RV Tei index correlated with the changes in clinical status in $\mathrm{PH}$ patients [22]. Hsiao et al. reported increased RV Tei index in $40 \mathrm{SSc}$ patients compared to 45 controls [23]. Another echocardiographic parameter of RV systolic function impairment which we assessed in the present study was TAPSE. In our SSc group of patients, the mean value of TAPSE was significantly decreased compared to controls. In total, there have been $>40$ studies with $>2,000$ normal subjects evaluating the utility of TAPSE [20]. To date, there are only a few studies including TAPSE assessment in the SSc population. Mathai et al., in the group of $50 \mathrm{SSc}-$ related PAH subjects, revealed that TAPSE is a robust parameter of RV function and strongly predicts survival in this group [24]. Moreover, in our study, we found shorter AcT in SSc patients than in controls suggesting disturbed coupling to the pulmonary arterial bed. Our findings therefore confirm that SSc patients can be characterized by RV dysfunction in echocardiography and suggest that the use of novel indicators such as TAPSE and RV Tei index can be useful in evaluating the RV function in SSc patients. A 6MWT is recommended for prognostic evaluation in PAH patients, because it is a strong and independent mortality predictor and correlates with the NYHA/WHO classification [25]. As we expected, in our study, patients with SSc had a statistically significant shorter 6MWT distance than the control group $(p=0.03)$ which is in accordance with the previous studies [26, 27]. What is new is that the mean 6MWT distance was significantly shorter in the highest NT-proBNP tertile group than in the lowest one $(p=0.04)$, pointing that the distance achieved during the 6MWT not only is depending on the patient's joint and muscle problems but also is the indicator of heart involvement in SSc patients

The main aim of our study was to assess if biochemical markers of right ventricular overload, endothelial dysfunction and collagen metabolism can predict RV dysfunction assessed

Table 5 Clinical and echocardiographic parameters according to the NTproBNP level

\begin{tabular}{lllc}
\hline Parameter & $\begin{array}{l}\text { NT-proBNP } \\
<88 \mathrm{pg} / \mathrm{ml} \text { (the } \\
\text { lowest tertile, } \\
n=31)\end{array}$ & $\begin{array}{l}\text { NT-proBNP } \\
>195 \mathrm{pg} / \mathrm{ml} \text { (the } \\
\text { highest tertile, } \\
n=32)\end{array}$ & $p$ value \\
\hline Age (years) & $48.29 \pm 13.24$ & $64.40 \pm 9.87$ & $<0.0001$ \\
BSA (m $\left.{ }^{2}\right)$ & $1.78 \pm 0.23$ & $1.63 \pm 0.18$ & 0.01 \\
AcT (ms) & $123.54 \pm 22.77$ & $112.34 \pm 20.35$ & 0.04 \\
RV Tei index & $0.34 \pm 0.07$ & $0.39 \pm 0.1$ & 0.03 \\
TRPG (mmHg) & $23.7 \pm 4.25$ & $30.0 \pm 9.14$ & 0.004 \\
IVC inspiration (mm) & $13.16 \pm 3.0$ & $15.09 \pm 2.66$ & 0.003 \\
6MWT (m) & $534 \pm 106$ & $456 \pm 96$ & 0.04 \\
\hline
\end{tabular}


by Doppler echocardiography. We found that serum levels of NT-proBNP and ET-1 were significantly higher in SSc patients than in controls. Moreover, we revealed that SSc patients with serum NT-proBNP levels in the highest tertile had more pronounced RV dysfunction than the group in the lowest tertile. NT-proBNP serum concentration correlated positively with echocardiographic indices of RV overload: TRPG and RV Tei index. Williams et al. in the group of 109 SSc patients reported significantly higher serum NT-proBNP level in 68 patients with PAH than without PAH $(1,474$ vs $139 \mathrm{pg} / \mathrm{ml}, p=0.002)$. They also found significant correlations between NT-proBNP serum level and mean pulmonary artery pressure $(r=0.62, p<0.0001)$ and pulmonary vascular resistance $(r=0.81, p<0.0001)$ [28]. Dimitroulas at al. analysed data of 66 patients with SSc. Similar to our findings, they revealed significantly increased serum NT-proBNP level in SSc patients with echocardiographic signs of $\mathrm{PH}(370.5$ [224.9-606.7] vs 256.1 [197.3-351.7]fmol/1, $p=0.012$ ) (179). NT-proBNP (OR per $10 \mathrm{fmol} / \mathrm{l}$ increase 1.03; $95 \%$ CI 1.00-1.05) was the univariate correlate of the presence of $\mathrm{PH}[5]$.

The authors of recent published results of the DETECT study proposed the first evidence-based detection algorithm for PAH in SSc. According to this data, serum NT-proBNP level is a useful marker in the algorithm for early identification of PAH in a mildly symptomatic population [29].

In our SSc group of patients, the ROC analysis revealed that the serum NT-proBNP level $195 \mathrm{pg} / \mathrm{ml}$ showed a sensitivity of $75 \%$ and a specificity of $67 \%$ for SSc-related RV overload. Oravec et al. in the group of $119 \mathrm{SSc}$ patients reported that the serum NT-proBNP level $157.8 \mathrm{pg} / \mathrm{ml}$ showed $100 \%$ sensitivity, $72.3 \%$ specificity, $39.1 \%$ PPV and $100 \%$ NPV for detected PH [30]. We also revealed using the ROC analysis that serum NT-proBNP level is useful in identification of RV Tei index $>0.4$. Moreover, the serum ET-1 level $1.85 \mathrm{pg} / \mathrm{ml}$ showed $69 \%$ sensitivity and $52 \%$ specificity for RV Tei index $>0.4$ detection. To our knowledge, this is the first such analysis in SSc patients.

We did not find significant differences in serum levels of ADMA, endoglin and TIMP-1 between SSc patients and controls. These biomarkers also did not correlate with echocardiographic indices of RV overload. Blaise et al. revealed increased mean ADMA concentrations in $39 \mathrm{SSc}$ patients than in controls $(0.68 \pm 0.12$ vs $0.62 \pm 0.12 \mu \mathrm{M}, p=0.002)$ [12]. Dimitroulas et al. reported higher plasma ADMA levels in SSc patients with $\mathrm{PH}$ compared to those without $\mathrm{PH}(p=$ 0.0008) [5]. In contrast, Wipff et al. did not find significant differences in serum ADMA levels between SSc and controls $(0.83 \pm 0.35$ vs $0.89 \pm 0.30 \mu \mathrm{mol} / 1, \mathrm{NS})$ [11]. There are several reports that serum levels of endoglin, a parameter of endothelial dysfunction, can be elevated in SSc patients [11, 31]. Some authors revealed that TIMP-1, a marker of decreased collagen metabolism, is increased in patients with SSc [12,
32]. Non-elevated levels of ADMA and endoglin in our group of SSc patients may be due to the fact that only $20(22 \%)$ of them presented RV overload (TRPG $>31 \mathrm{mmHg}$ ). Also, no significant differences in mean serum concentration of TIMP1 between SSc and control group can result from mild and moderate stages of SSc. Maybe after long-term follow-up and disease progression will the differences between biomarkers reach statistical significance.

This is a first study that explores the relationship between five different biomarkers and impaired RV function in SSc. Additional investigations in prospective studies are warranted to confirm our findings.

\section{Limitations of the study}

In our study, we did not estimate the impact of the lung function indices on the echocardiographic and biochemical parameters. To minimize the influence of the bronchial obstruction, we excluded patients with impaired results of spirometry. Also, more than $30 \%$ of SSc patients had mild to moderate lung fibrosis, which might have had some influence on the results.

\section{Conclusions}

Serum ET-1 and NT-proBNP, but not ADMA, endoglin and TIMP-1 levels correlating with the echocardiographic parameters of $\mathrm{RV}$ overload, can be considered as noninvasive indicators of $\mathrm{RV}$ dysfunction in SSc patients.

Acknowledgments This study was partially supported by grant NCN, UMO-2012/07/N/NZ5/01647.

\section{Disclosures None.}

Open Access This article is distributed under the terms of the Creative Commons Attribution License which permits any use, distribution, and reproduction in any medium, provided the original author(s) and the source are credited.

\section{References}

1. Steen V (2005) Advancements in diagnosis of pulmonary arterial hypertension in scleroderma. Arthritis Rheum 52(12):3698-700

2. Zuhur F, Zuhur SS, Zuhur C, Musellim B, Ongen G (2012) Survival in progressive systemic sclerosis with pulmonary involvement: a single-center experience in Istanbul, Turkey. Rheumatol Int 32: 1655-61

3. Elhai M, Meune C, Avouac J, Kahan A, Allanore Y (2012) Trends in mortality in patients with systemic sclerosis over 40 years: a systematic review and meta-analysis of cohort studies. Rheumatology (Oxford) 51(6):1017-26 
4. Komocsi A, Vorobcsuk A, Faludi R, Pinter T, Lenkey Z, Kolto G et al (2012) The impact of cardiopulmonary manifestations on the mortality of SSc: a systematic review and meta-analysis of observational studies. Rheumatol (Oxford) 51(6):1027-36

5. Dimitroulas T, Giannakoulas G, Papadopoulou K, Sfetsios T, Karvounis H, Dimitroula H et al (2010) Left atrial volume and $\mathrm{N}$-terminal pro-B type natriuretic peptide are associated with elevated pulmonary artery pressure in patients with systemic sclerosis. Clin Rheumatol 29(9):957-64

6. Galie N, Hoeper MM, Humbert M, Torbicki A, Vachiery JL, Barbera JA et al (2009) Guidelines for the diagnosis and treatment of pulmonary hypertension: the Task Force for the Diagnosis and Treatment of Pulmonary Hypertension of the European Society of Cardiology (ESC) and the European Respiratory Society (ERS), endorsed by the International Society of Heart and Lung Transplantation (ISHLT). Eur Heart J 30(20):2493-537

7. Coral-Alvarado P, Quintana G, Garces MF, Cepeda LA, Caminos JE, Rondon $\mathrm{F}$ et al (2009) Potential biomarkers for detecting pulmonary arterial hypertension in patients with systemic sclerosis. Rheumatol Int 29(9): 1017-24

8. Emdin M, Marini C, Passino C (2011) Right ventricular overload and cardiovascular neuroendocrine derangement in systemic sclerosis. Eur Heart J 6(suppl F):F68-F73

9. Mukerjee D, Yap LB, Holmes AM, Nair D, Ayrton P, Black CM et al (2003) Significance of plasma N-terminal pro-brain natriuretic peptide in patients with systemic sclerosis-related pulmonary arterial hypertension. Respir Med 97(11):1230-6

10. Dimitroulas T, Giannakoulas G, Sfetsios T, Karvounis H, Dimitroula $\mathrm{H}$, Koliakos G et al (2008) Asymmetrical dimethylarginine in systemic sclerosis-related pulmonary arterial hypertension. Rheumatol (Oxford) 47(11):1682-5

11. Wipff J, Avouac J, Borderie D, Zerkak D, Lemarechal H, Kahan A et al (2008) Disturbed angiogenesis in systemic sclerosis: high levels of soluble endoglin. Rheumatol (Oxford) 47(7):972-5

12. Blaise S, Maas R, Trocme C, Kom GD, Roustit M, Carpentier PH et al (2009) Correlation of biomarkers of endothelium dysfunction and matrix remodeling in patients with systemic sclerosis. J Rheumatol 36(5):984-8

13. No authors listed (1980) Preliminary criteria for the classification of systemic sclerosis (scleroderma). Subcommittee for scleroderma criteria of the American Rheumatism Association Diagnostic and Therapeutic Criteria Committee. Arthritis Rheum 23(5):581-90

14. Valentini G, Bencivelli W, Bombardieri S, D'Angelo S, Della RA, Silman AJ et al (2003) European Scleroderma Study Group to define disease activity criteria for systemic sclerosis III. Assessment of the construct validity of the preliminary activity criteria. Ann Rheum Dis 62(9):901-3

15. Tei C, Dujardin KS, Hodge DO, Bailey KR, McGoon MD, Tajik AJ et al (1996) Doppler echocardiographic index for assessment of global right ventricular function. J Am Soc Echocardiogr 9(6):83847

16. Feigenbaum H, Armstrong WF, Ryan T (2005) Feigenbaum's echocardiography, 6th edn. Lippincott, Williams\&Wilkins, Philadelphia

17. ATS Committee on Proficiency Standards for Clinical Pulmonary Function Laboratories (2002) ATS statement: guidelines for the sixminute walk test. Am J Respir Crit Care Med 166(1):111-117

18. Chung L, Liu J, Parsons L, Hassoun PM, McGoon M, Badesch DB et al (2010) Characterization of connective tissue disease-associated pulmonary arterial hypertension from REVEAL: identifying systemic sclerosis as a unique phenotype. Chest 138(6):1383-94
19. Trad S, Amoura Z, Beigelman C, Haroche J, Costedoat N, le Boutin $\mathrm{TH}$ et al (2006) Pulmonary arterial hypertension is a major mortality factor in diffuse systemic sclerosis, independent of interstitial lung disease. Arthritis Rheum 54(1):184-91

20. Rudski LG, Lai WW, Afilalo J, Hua L, Handschumacher MD, Chandrasekaran $\mathrm{K}$ et al (2010) Guidelines for the echocardiographic assessment of the right heart in adults: a report from the American Society of Echocardiography endorsed by the European Association of Echocardiography, a registered branch of the European Society of Cardiology, and the Canadian Society of Echocardiography. J Am Soc Echocardiogr 23(7):685-713

21. Yeo TC, Dujardin KS, Tei C, Mahoney DW, McGoon MD, Seward JB (1998) Value of a Doppler-derived index combining systolic and diastolic time intervals in predicting outcome in primary pulmonary hypertension. Am J Cardiol 81(9):1157-61

22. Sebbag I, Rudski LG, Therrien J, Hirsch A, Langleben D (2001) Effect of chronic infusion of epoprostenol on echocardiographic right ventricular myocardial performance index and its relation to clinical outcome in patients with primary pulmonary hypertension. Am J Cardiol 88(9):1060-3

23. Hsiao SH, Lee CY, Chang SM, Lin SK, Liu CP (2006) Right heart function in scleroderma: insights from myocardial Doppler tissue imaging. J Am Soc Echocardiogr 19(5):507-14

24. Mathai SC, Sibley CT, Forfia PR, Mudd JO, Fisher MR, Tedford RJ et al (2011) Tricuspid annular plane systolic excursion is a robust outcome measure in systemic sclerosis-associated pulmonary arterial hypertension. J Rheumatol 38(11):2410-8

25. Miyamoto S, Nagaya N, Satoh T, Kyotani S, Sakamaki F, Fujita M et al (2000) Clinical correlates and prognostic significance of sixminute walk test in patients with primary pulmonary hypertension. Comparison with cardiopulmonary exercise testing. Am J Respir Crit Care Med 161(2 Pt 1):487-92

26. Ciurzynski M, Bienias P, Lichodziejewska B, Kurnicka K, Szewczyk A, Glinska-Wielochowska $M$ et al (2008) Non-invasive diagnostic and functional evaluation of cardiac involvement in patients with systemic sclerosis. Clin Rheumatol 27(8):991-7

27. Huez S, Roufosse F, Vachiery JL, Pavelescu A, Derumeaux G, Wautrecht JC et al (2007) Isolated right ventricular dysfunction in systemic sclerosis: latent pulmonary hypertension? Eur Respir J 30(5):928-36

28. Williams MH, Handler CE, Akram R, Smith CJ, Das C, Smee J et al (2006) Role of N-terminal brain natriuretic peptide (N-TproBNP) in scleroderma-associated pulmonary arterial hypertension. Eur Heart J 27(12):1485-94

29. Coghlan JG, Denton CP, Grunig E, Bonderman D, Distler O, Khanna D, et al (2013) Evidence-based detection of pulmonary arterial hypertension in systemic sclerosis: the DETECT study. Ann Rheum Dis (in press)

30. Oravec RM, Bredemeier M, Laurino CC, Pinotti AF, Rohde LE, Brenol JC et al (2010) NT-proBNP levels in systemic sclerosis: association with clinical and laboratory abnormalities. Clin Biochem 43(9):745-9

31. Coral-Alvarado PX, Garces MF, Caminos JE, Iglesias-Gamarra A, Restrepo JF, Quintana G (2010) Serum endoglin levels in patients suffering from systemic sclerosis and elevated systolic pulmonary arterial pressure. Int J Rheumatol. doi:10.1155/2010/ 969383

32. Young-Min SA, Beeton C, Laughton R, Plumpton T, Bartram S, Murphy $G$ et al (2001) Serum TIMP-1, TIMP-2, and MMP-1 in patients with systemic sclerosis, primary Raynaud's phenomenon, and in normal controls. Ann Rheum Dis 60(9):846-51 